\title{
迅ectures
}

ON

\section{ORTHOPADIC SURGERY.}

BY

BERNARD E. BRODHURST, F.R.C.S.,

OF ST. GEORGE'S HOSPITAL, AND TIE ROYAI ORTHOPADIC HOSPITAL, ETC.

LECTURE XV.

ON TALIPES, OR CLUB-FOOT. (Continued.)

Talipes Valgus occurs both as a congenital and a non-congenital deformity. As compared with talipes varus, it is a rare form of congenital deformity; but it is a very common non-congenital affection.

The external characters of this deformity are in some measure expressed in the name by which it is known, which signifies that the foot is twisted outwards. Thus the inner margin of the foot is depressed, while the outer is more or less raised; and the sole presents outwards. From its nomenclature, it would be supposed that this deformity was the reverse of talipes varus; and, if this is not absolutely the case, the name is sufficiently well given, for it expresses the most prominent external characteristic -namely, that the foot is inclined outwards. The general appearance of the deformity, as it is seen in the young child, is shown in the following figure.

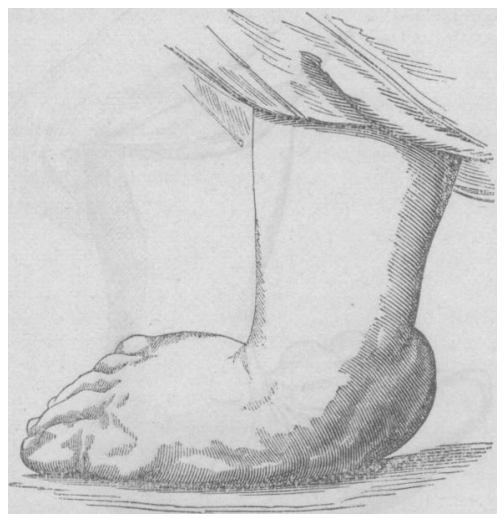

Fig. 44.

When the child begins to walk, the great inconvenience of the deformity shows itself. Not only is much lameness produced by the shape which the foot assumes, but pressure on the ground, as in walking, becomes excessively painful. It is only necessary to see such a figure as the following, for instance, to feel sure that such must undoubtedly be the case. The weight of the body is borne on the inner margin of the foot; and pressure may induce ulceration of the integument and troublesome sloughs. This is rare, however. Occasionally, walking becomes impossible without crutches or supports of some kind.

Morbid Anatomy. The following figure (Fig. 45) represents a severe form of congenital deformity; and yet, even where the deformity is so great, there is seldom to be found any deviation from the normal forms of the tarsal bones. The os calcis always deviates somewhat from its normal position, the tuber calcis being drawn upwards by the tendo Achillis

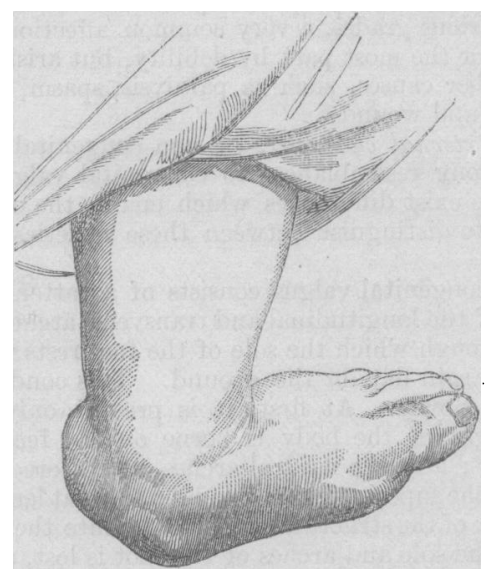

Fig. 45.

and the powerful contraction of the muscles of the calf of the leg. In one case which he examined, Mr. Adams found the tuberosity of the os calcis as much elevated as it is in a severe example of congenital varus. The astragalus lies somewhat obliquely ; and its head presents beneath the skin on the inner margin of the foot, and is partly uncovered by the navicular bone. The prominence which is formed by it may always be distinguished in congenital valgus. 'The longitudinal and transverse arches of the foot are obliterated, and even they may be reversed; so that the plantar surface shall present a convex instead of its usual concave form. The scaphoid, cuneiform, and cuboid bones, together with the metatarsal bones, are all more or less altered, not in shape, but in their positions, both absolutely and relatively as regards each other; and the foot is bent upon itself, and everted at the transverse tarsal joint. The following figure shows this better, perhaps, than either of the preceding. (Fig. 46.)

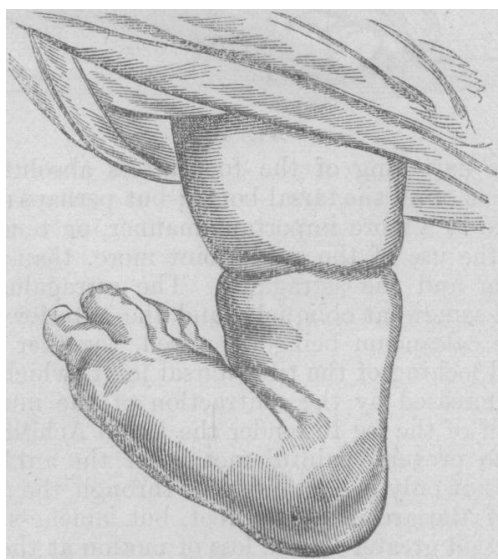

Fig. 46.

The muscles which are especially active in this deformity are the peronei and the extensor longus 
digitorum; but also, in general, the muscles of the calf of the leg are retracted, and become serious obstacles in the mechanical treatment of this deformity. The strong ligaments and fasciæ in the sole of the foot are lengthened and much weakened.

Non-congenital Talipes Valgus is, in one or other of its various grades, a very common affection, occasioned for the most part by debility, but arising also from other causes, such as paralysis, spasm, inflammation, and wounds.

The external characters of non-congenital valgus have strong resemblances to congenital valgus, and yet there exist differences which enable the observer at once to distinguish between these varieties of deformity.

Non-congenital valgus consists of a flattened condition of the longitudinal and transverse arches of the foot, through which the sole of the foot rests with its inner margin flat on the ground. This condition is induced slowly. At first, it is present only when the weight of the body is borne on the feet, as in standing; and the natural arches are restored on removing the superincumbent weight. But at length the elasticity of the structures which enter into the formation of the sole and arches of the foot is lost, and the foot remains flat. In proportion as the arches are flattened, so is the height of the instep diminished, and the foot becomes somewhat elongated and everted; and, in consequence of these changes, the internal malleolus is brought absolutely nearer to the ground, and its prominence is increased in proportion to the eversion of the foot. These points are shown in the following figure. (Fig. 47.)

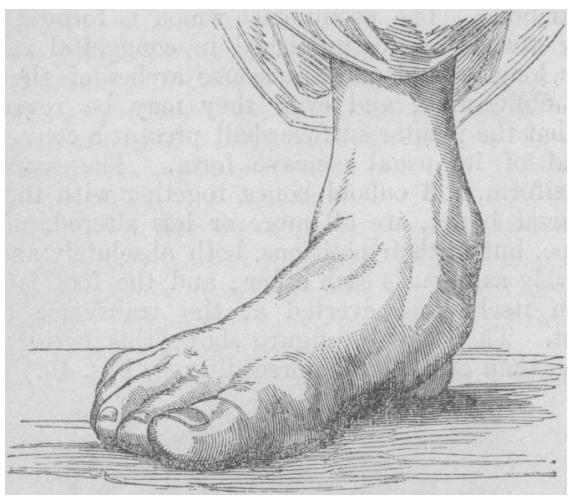

Fig. 47.

This flattening of the foot alters absolutely the positions of all the tarsal bones; but perhaps none are affectcd in a more important manner, or tend to destroy the use of the ankle-joint more, than the calcaneum and the astragalus. 'The astragalus being placed somewhat obliquely, and the anterior surface of the calcaneum being depressed, together cause a partial locking of the tibio-tarsal joint, which is further increased by the contraction of the muscles of the calf of the leg to render the tendo Achillis tense; thus to prevent painful motion at the ankle-joint. 'Thus, not only is elasticity lost through the destruction of the arches of the foot, but lameness is rendered still greater by the loss of motion at the anklejoint. 'The arches of the foot are destroyed, compressing very painfully the soft structures of the sole in walking (see Fig. 48); and the deformity may even increase to produce a convex surface towards the ground-the reverse of the natural arches of the foot.

One of the most severe forms of this distortion that has perhaps ever been witnessed, was lately under my care at St. George's Hospital. It was induced

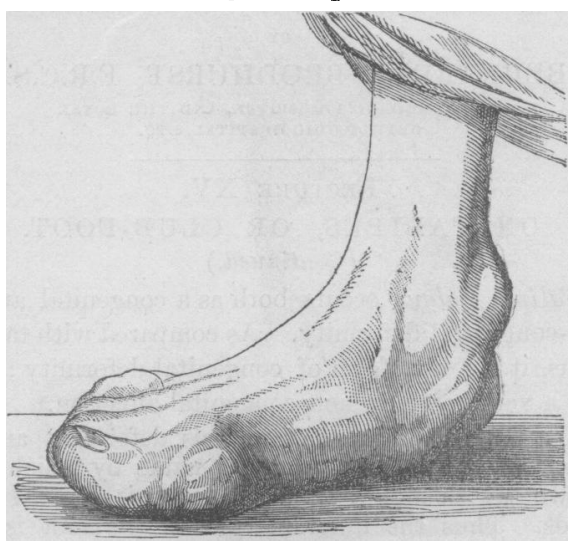

Fig. 48.

as a consequence of extensive ulceration on the dorsum of the foot and by cicatrisation in healing. In this instance, the arches of the foot were absolutely reversed; the foot was much everted and flexed, and its outer margin was raised; the tendo Achillis was tense; and there was scarcely perceptible motion at the ankle-joint. 'The following illustrations show the deformity well. (Figs. 49 and 50.)

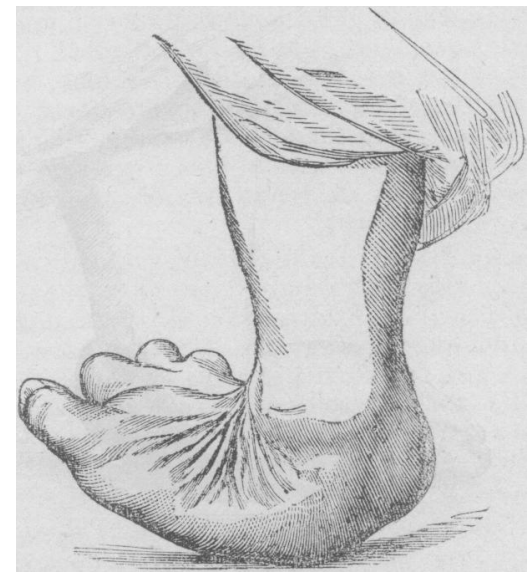

Fig. 49.

The Treatment of Concienital Valgus varies somewhat according to the degree of deformity which has to be removed. Just as in varus, slight cases of deformity may be treated by mechanical means alone, and without the division of tendons. It is only justifiable, however, to recommend such a course when the deformity is so slight that the treatment may safely be left in the hands of a judicious nurse. In an ordinary case, this mechanical treatment would occupy many months, and it might probably then not be successful.

Lately, I saw a case of congenital valgus, of not a severe grade, which had been treated mechanically for several months, with very little gain except to 
the surgeon himself, when he proposed to divide the tendons; for he was then convinced that the operation was necessary. The operation was performed, not however by the bandagist, and the deformity was entirely removed in six weeks.

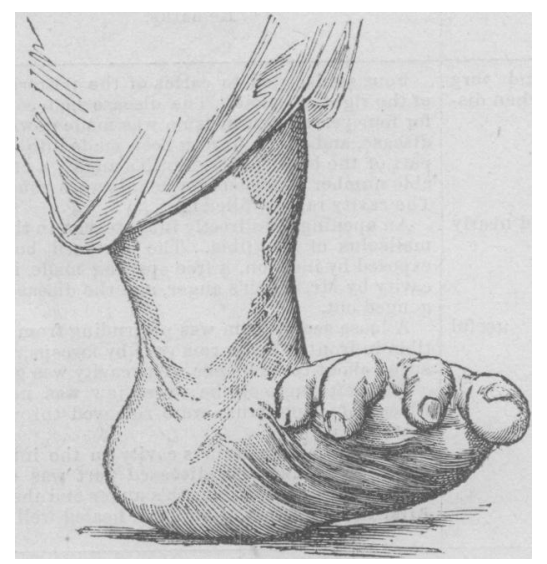

Fig. 50.

But if, at a tender age, these efforts of bandaging are futile, how much more so must they be in congenital cases at a more advanced age. In many of these cases, the most perfectly adapted mechanism will scarcely avail to remove deformity even after the section of tendons and fasciæ. In the majority of cases, it is sufficient to divide the peronei tendons. If, however, the extensor longus digitorum muscle is retracted, its tendons should also be divided. Then, after the punctures have healed, the foot may be gently and gradually inverted and restored to its normal form, being bound to a pliable splint. In instances of severe distortion, it is frequently necessary, also, to divide the tendo Achillis after the foot has been fully inverted.

In the adult, the treatment will probably occupy as many months as it occupied weeks in the infant. A well adjusted mechanical shoe will be required to remove deformity after the tendons have been divided. The improved instruments which are now in use for the treatment of these cases are very powerful; and they require nice management, lest so much force should be exerted as to injure the soft structures.

The Treatment of Non-Congenital Valgus will vary according to the degree of deformity and the eause which gave rise to it. A very large majority of these cases depend on debility; and the deformity may be removed by local support, and by general tonic treatment and rest. No treatment will avail anything without rest-that is to say, rest to the overworked lower limbs.

In paralytic valgus, the deformity may generally be overcome without operation and by mechanical means only. When the affection is recent, this may always be done, and even there is then hope of partial recovery, at least, of muscular power, when attention is given to the cause of paralysis, and means are taken to excite the affected muscles. When the deformity is of long standing, the loss of power will probably remain ; and, in consequence of structural shortening which will probably have taken place, one or more tendons may require to be divided. In these cases, however, the comfort and power which are given by restoring the normal shape of the foot, and by well adjusted mechanical support, are worth anything to one who has been long crippled. Such support may probably be necessary during the remainder of life, that contraction may not again occur.

Spasmodic valgus is rare. It is a sequel of convulsive action, perhaps occasioned by teething or by some other irritating cause; and it remains, for some years perhaps, just as, in another instance, strabismus may remain, or equinus, or any other muscle or group of muscles may remain affected. Without, however, an epileptic condition or a morbidly excitable nervous condition continues, this spasmodic muscular action will probably diminish, and at length cease altogether, without division of tendons. It is necessary to attend to the exciting cause of spasmodic action, rather than to the manifestation itself. Wherever disease of the nervous centres remains, no idea of section of tendons can be entertained; but when irritation and disease have entirely passed away, and this habit (so to say) of increased muscular action is left as the sole indication of former disease, it may be justifiable to divide a tendon and thus to restore the use of a limb.

Inflammation about the foot and ankle-whether by inducing thickening and softening of ligaments and other soft structures, or by causing loss of substance and subsequent contraction-may give rise to valgus ; and there is no form in which this deformity can present itself that is more obstinate or difficult to control than this arising from inflammation. A severe case is well nigh hopeless: if it be of long standing, it is intractable; and when it is recent, wounds and sloughs readily form. The only manner in which these cases can be mastered, is to encase the limb in cerate on strips of kid, and then to apply mechanical means as gently as possible.

When the ankle-joint itself has been affected, and partial ankylosis remains as a result of inflammation, the greatest benefit may be derived, after inflammation has entirely ceased, from the section of such tendons as may tend to impede motion. It is rare, however, that the tendons themselves have to be divided. For the most part, it is alone necessary to break through the adhesions after chloroform has been fully administered.

After deformity has been removed, the use of the limb may be regained by various well adapted movements, galvanism, shampooing, the hot air bath, and such other means as may be indicated by the cause and nature of the affection itself. It is necessary, in all cases of this description, that mechanical support shall be worn until the control of the limb has been gained.

London Frver Hospital. Mr. Charles sijuarey, the house-surgeon of the Fever Hospital, is suffering from an attack of typhus fever, which he has no doubt taken in the discharge of his onerous and dangerous duties. Mr. Squarey for many months during 1863 acted as one of the resident surgeons of the hospital, so that this is a second occasion upon which he has so courageously volunteered to do batte against the insidious attacks of fever to which the unusually numerous patients admitted into the hospital during the last year have been subjected. 


\section{LEEDS GENERAL INFIRMARY.}

Statistical Tables of the Operations performed from January to June, 1864, inclusive. Operations for Necrosis and Caries of Bone.

\begin{tabular}{|c|c|c|c|c|c|c|}
\hline No. & $\begin{array}{l}\text { Sex } \\
\text { and } \\
\text { age. }\end{array}$ & Operator. & Nature of operation. & $\begin{array}{l}\text { Stay in } \\
\text { Hospital } \\
\text { after } \\
\text { operation. }\end{array}$ & Result. & Remarks. \\
\hline 1 & M. 14 & Mr. Teale & $\begin{array}{l}\text { Removal by gouge } \\
\text { of carious part of os } \\
\text { calcis. }\end{array}$ & 43 days & $\begin{array}{l}\text { Cured. Wound very } \\
\text { nearly healed when dis. } \\
\text { charged. }\end{array}$ & $\begin{array}{l}\text { Four sinuses led to caries of the posterior part } \\
\text { of the right os calcis. 'The disease had continued } \\
\text { for four years. An incision was made down to the } \\
\text { disease, and a hole having been made into the back } \\
\text { part of the bone by Mr. Smith's auger, a consider- } \\
\text { able number of carious fragments were gouged out. } \\
\text { The cavity rapidly filled up. }\end{array}$ \\
\hline 2 & F. 19 & Mr. S. Hey & $\begin{array}{l}\text { Gouging of carious } \\
\text { cavity in inner mal. } \\
\text { leolus. }\end{array}$ & 55 days & $\begin{array}{l}\text { Cured. Wound nearly } \\
\text { closed. }\end{array}$ & $\begin{array}{l}\text { An opening led directly into a cavity in the inner } \\
\text { malleolus of the tibia. The diseased bone was } \\
\text { exposed by incision, a free opening mate into the } \\
\text { cavity by Mr. Smith's auger, and the diseased bone } \\
\text { gouged out. }\end{array}$ \\
\hline 3 & M. 8 & Mr. S. Hey & $\begin{array}{l}\text { Removal of seques- } \\
\text { trum. }\end{array}$ & 15 days & $\begin{array}{l}\text { Cured, with useful } \\
\text { limb. }\end{array}$ & $\begin{array}{l}\text { A loose sequestrum was protruding from the left } \\
\text { tibin in front. When removed by forceps, it mea- } \\
\text { sured about three inches. The cavity was gonged. }\end{array}$ \\
\hline 4 & F. 5 & Mr. Nunneley & $\begin{array}{l}\text { Removal of seques. } \\
\text { trum. }\end{array}$ & 20 days & Cured. & $\begin{array}{l}\text { The left angle of the lower jaw was necrosed. } \\
\text { Pieces of sequestrum were removed through the } \\
\text { mouth. }\end{array}$ \\
\hline 5 & M. 16 & Mr. S. Hey & Gouging os ealcis. & 33 days & Cured. & $\begin{array}{l}\text { Sinuses led to a carious cavity on the inner side } \\
\text { of the os calois. The diseased part was exposed } \\
\text { and removed by Mr. Smith's anger and the gouge. } \\
\text { After the operation, the wound lealed well. }\end{array}$ \\
\hline
\end{tabular}

Removal of Innocent Tumours.

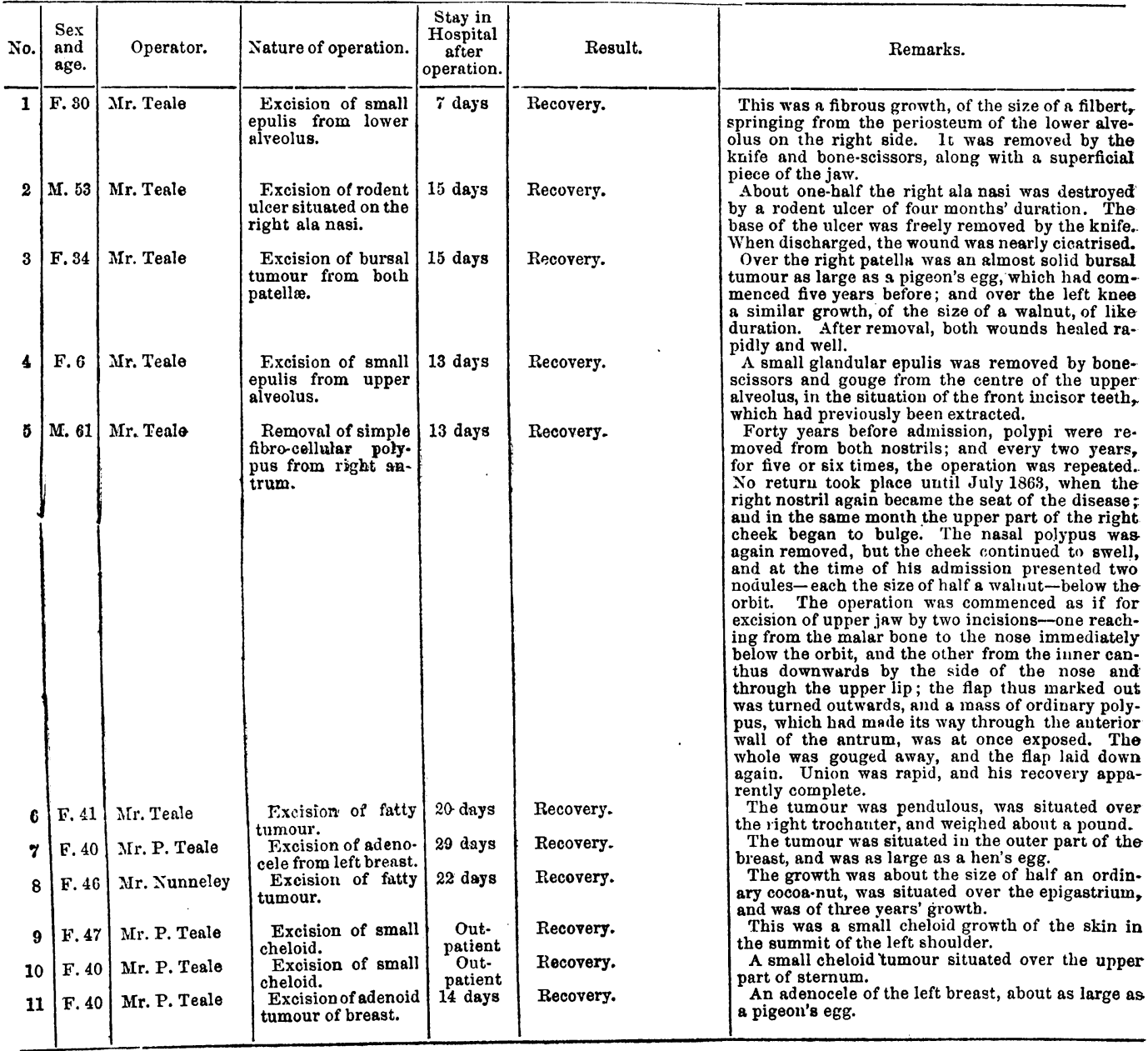


Operations for the Cure of Aneurism, Ncevus, etc.

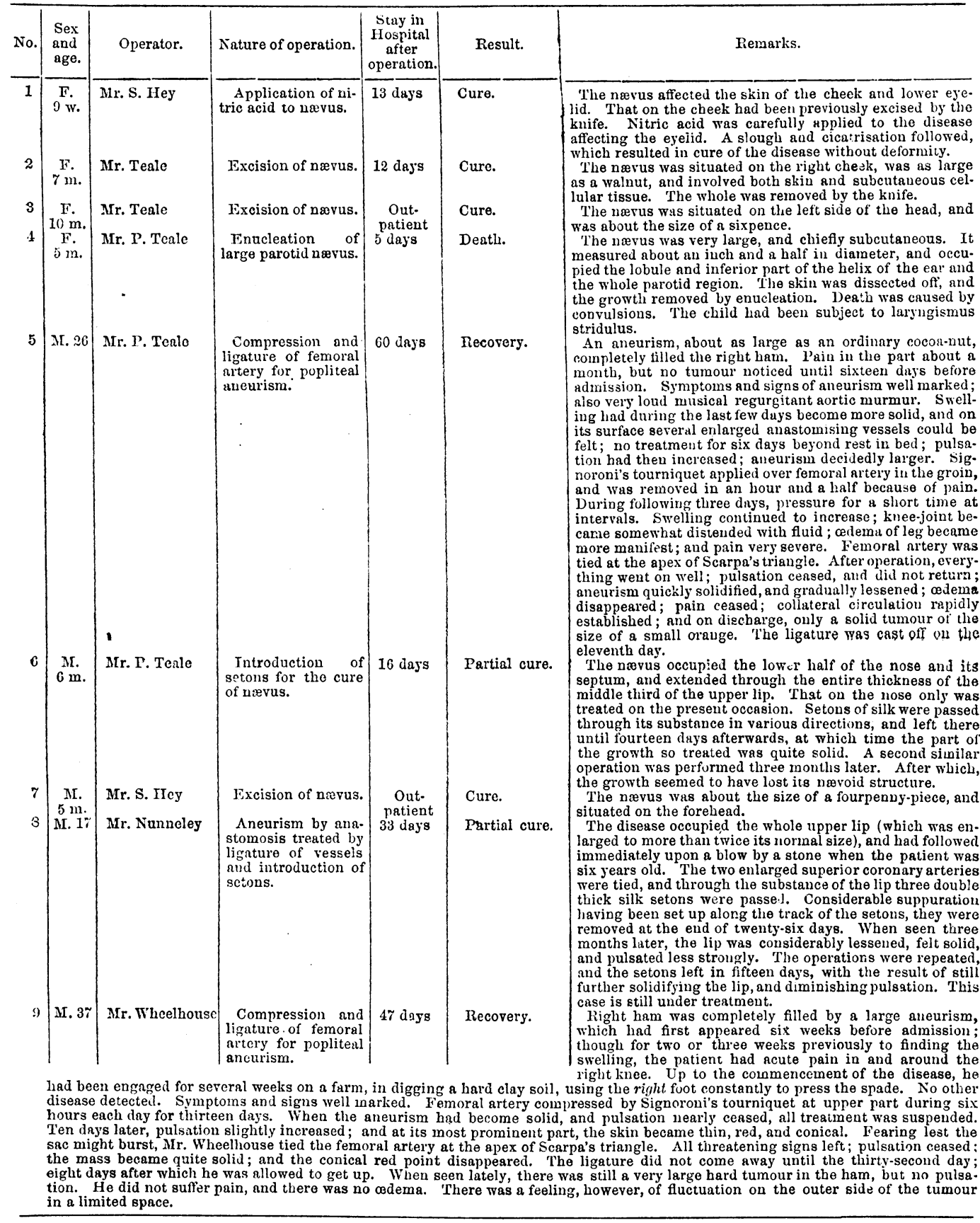

Excisions of Joints of Bones.

\begin{tabular}{|c|c|c|c|c|c|c|}
\hline 1 & F.26 & Mr. Teale & $\begin{array}{l}\text { Excision of os } \\
\text { calcis. }\end{array}$ & & $\begin{array}{l}\text { Recovery, with } \\
\text { useful foot. }\end{array}$ & $\begin{array}{l}\text { Kight neel had become the seat of disease three year } \\
\text { before. At the tims of admission, six sinuses-all leadin } \\
\text { to the os calcis, which was felt bare - surrounded the heel }\end{array}$ \\
\hline & \multicolumn{6}{|c|}{$\begin{array}{l}\text { With the view of picking out any bones of the tarsus which might be found in a diseased condition, Mr. Teale made two incisions-one } \\
\text { transrersely across the sole opposite and down to the calcaneo-cuboid joint, the other commencing at ihe outer extremity of the first } \\
\text { and extending directly backwards along the outer border of the heel as far as the insertion of the tendo Achillis; and thus was mapped } \\
\text { out a large flap, comprising the whple of the tissues of the heel, which was dissected up and turned inwards. As the os calcis alone was } \\
\text { found to be in a carious condition, it was removed, whilst the other bones were left. The flap lived and united well; and at the time of } \\
\text { her discharge the wound had nearly closed. When seen some months afterwards. the foot was quite sound; and, with the exception of } \\
\text { a little puckering, there was no deformity. She had not then tried to walk upon it, but was ordered to do so. }\end{array}$} \\
\hline
\end{tabular}

